\title{
Solving microcharacterisation problems in industry through the use of mapping
}

\author{
Colin M. MacRae ${ }^{*}$, S. Glanvill ${ }^{* * *}$, C.G. Ryan ${ }^{* *}$, C. Rossouw ${ }^{* * *}$, N.C. Scarlett ${ }^{*}$ and N.C. Wilson ${ }^{*}$ \\ * Microbeam Laboratory CSIRO Minerals, Bayview Avenue, Clayton, Australia, 3168 \\ ** CSIRO Exploration of Mining, PO Box 136, North Ryde, Australia, 2113 \\ *** CSIRO Manufacturing Infrastructure and Technology, Bayview Avenue, Clayton, Australia, 3168
}

A significant advancement in electron microprobe mapping has been the combined collection of whole cathodoluminescence (CL) spectra with X-ray and backscattered electron emission at each pixel $^{1}$. While this has significantly aided in discrimination of phases, the volume of data available to be interrogated by the analyst has increased significantly. Data visualisation tools such as Chimage software $^{2}$, must now do more than simply allow the industrial scientist to integrate the chemical and textural information, they must also offer a range of options such as cluster recognition techniques. In addition many industrial problems require more than one instrument to be used to solve the problem. A number of industrial problems and their solutions are given in this review paper.

Zircon grains from Bangladesh that contained high radioactive levels have been analysed by electron microprobe. Cathodoluminescence spectra and X-ray element distribution maps of polished zircon grains were acquired ${ }^{3}$. Inspection of the combined dataset using Chimage enabled correlations between chemistry and internal grain structure to be determined. This method offers significant benefits over traditional $\mathrm{CL}$ and BSE techniques in that direct comparison with the elemental concentrations over the same region is now achievable. By combining the electron microprobe results with data for the same mapped region obtained via a nuclear microprobe, significantly better detection limits $(\sim 1 \mathrm{ppm})$ for elements with atomic numbers greater than iron are possible. The ability to measure spatially related analytical data and then investigate correlations between the CL spectra and the chemical data is an important advancement in the characterisation of CL active minerals.

The chemical and structural location of cobalt in nickel laterite ores from eastern Australia has been another industrial microcharacterisation problem. Processed samples that contain unleached Co have been investigated using an electron microprobe to determine elemental associations with the cobalt. This study showed the location of Co rich regions within grains. The Co was found to be associated with both $\mathrm{Fe}$ and $\mathrm{Cr} \mathrm{X}$-rays. This suggested a number of possible minerals that were locking the Co that needed confirmation. Selected grains containing high levels of Co, $\sim 5 \mathrm{wt} \%$, of up to $100 \mu \mathrm{m}$ were removed from the polished mount and mounted for transmission electron microscopy (TEM) examination. The Co rich grains were highly magnetic requiring them to be mounted in epoxy and prepared using ultra-microtomy techniques. Sections up to $150 \mathrm{~nm}$ thick were prepared using this technique and examined using a Philips CM30 TEM operated at 200kV. The TEM was equipped with an $\mathrm{Si}(\mathrm{Li})$ energy dispersive detector which was used to collect elemental X-ray maps of potential Co rich regions. The identification of the Co rich areas proved difficult due to the overlap between $\mathrm{Fe} ; \mathrm{K} \beta$ and $\mathrm{Co} ; \mathrm{K} \alpha$. X-ray maps were collected for over an hour and these proved to have sufficient statistics to allow the peak deconvolution algorithms to separate $\mathrm{Co} ; \mathrm{K} \alpha$ when $\mathrm{Co}$ was present in levels over $5 \mathrm{wt} \%$. A selected area diffraction pattern, Fig. 1, was acquired from an area containing $\mathrm{Co}$, and a $\mathrm{NiFe}$ oxide phase was identified as the mineral Trevorite, $\mathrm{NiFe}_{2} \mathrm{O}_{4}$. 
Elemental mapping using the electron microprobe has been extended through the application of Bence-Albee matrix corrections to provide semi-quantitative information by representing the data on an elemental weight scale rather than that of raw X-ray intensity. This enables data to be compared across a wide range of samples and collected under different analytical conditions. Automatic clustering can now be applied to this data and chemical relationships extracted and compared with structural information obtained from bulk samples using X-ray diffraction techniques. This has been successfully applied to the investigation of metal electrodes used in the production of aluminium. In particular the technique has been applied to the investigation of surface layers forming at the metalcryolite bath interface ${ }^{4}$.

\section{References}

[1] MacRae, C. M., Wilson, N. C., and Otsuki, M. Microscopy and Microanalysis. Long Beach, Calif. Bailey, G. W.(ed), New York, Springer. 2001. pp. 146-147

[2] Harrowfield, I. R., MacRae, C., and Wilson, N. C. Proceedings of the $27^{\text {th }}$ Annual MAS Meeting (Microbeam Analysis Society), vol. 1993. pp. 547-548

[3] MacRae C.M., Wilson N.C., Aral H., Ryan C.G., and Pownceby M.I. Heavy Minerals Conference 2003. South Africa. In press.

[4] Brown C.W. Technical program 132nd TMS Annual Meeting. JOM. Vol. 54, No 11, 2002. pp. 183

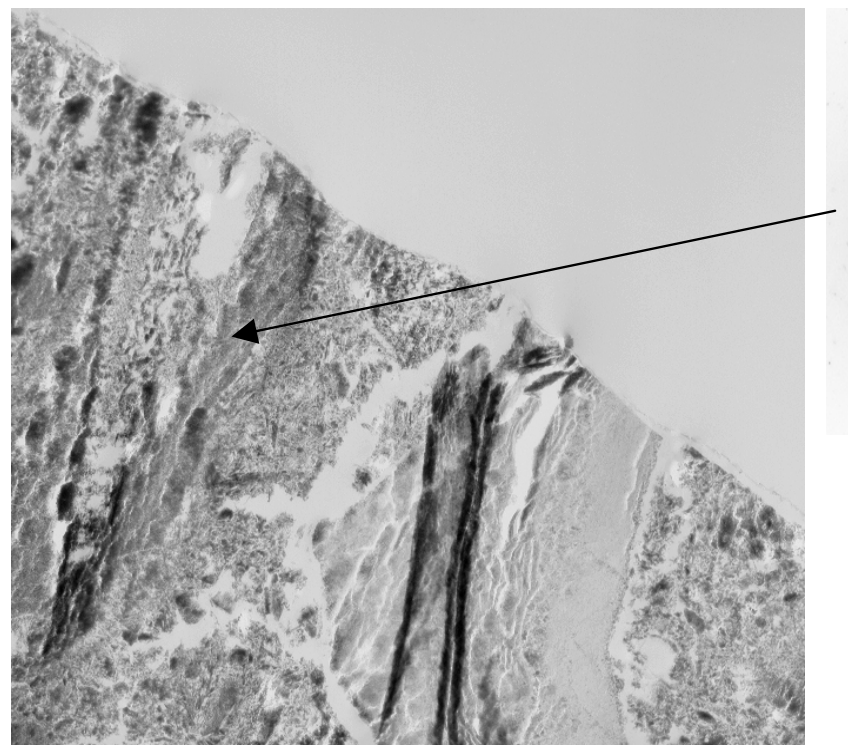

Trevorite

Figure 1. Transmission electron micrograph showing crystalline and amorphous regions within a Co rich section of a Ni laterite sample. The insert is the diffraction pattern of Trevorite, $\mathrm{NiFe}_{2} \mathrm{O}_{4}$. 